\title{
The Effects of Environment Parameter on the Decay of Total Residual Oxidant in Neutral Electrolyzed Sea Water
}

\author{
Dongxia Duan, Ping Yao, Guangzhou Liu, Xuelei Liu, and Hui Ding
}

\begin{abstract}
The introduction of invasive marine species into new environments by the ballast water of ships has been identified as one of the four greatest threats to the world's oceans. Many technologies have been developed for ballast water treatment among which electrolytic treatment method has been taken as the most promising one. The concentration of total residual oxidant was an important parameter to treat ballast water for electrolytic technology. In this paper, the effect of temperature and organic carbon on the decay of total residual oxidant in neutral electrolyzed water was investigated. The results showed that the total residual oxidant at $25^{\circ} \mathrm{C}$ decayed faster than that at lower temperature. Glucose and citrate could promote the decay of total residual oxidant while sucrose had no effect on total residual oxidant. For particle organic carbon, chitosan could promote the decay of total residual oxidant, while corn starch had no effect on the decay of total residual oxidant. Our results indicated that when initial total residual oxidant was decided, the temperature and kind and concentration of organic carbon should be taken into account.
\end{abstract}

Index Terms-Ballast water, total residual oxidant, neutral electrolyzed water, organic carbon.

\section{INTRODUCTION}

Ballast water contains a variety of organisms including bacteria and virus and the adult and larval stages of the many marine and coastal plants and animals [1]-[3]. These organisms in ballast water spread from one place to another place with ship. If these organisms established in a new place, it can have a serious ecological, economic and public health impact on the receiving environment [4], [5].

In the 2004, the International Maritime Organization (IMO) adopted the International Convention for the Control and Management of Ships' Ballast Water and Sediments (BWM Convention) to regulate the discharges of ballast water and reduce the risk of introducing non-native species from ship's ballast water. The need for ballast water treatment has arisen from the requirements of regulation D-2 of the BWM Convention. In response to this, a number of technologies have been developed. These technologies are generally can be divided to solid-liquid separation and disinfection process. In the process of solid-liquid separation, the solid material including the larger organisms in the marine was removed. The technologies often used in this process were filter

Manuscript received March 25, 2015; revised June 18, 2015. This work was supported in part by Department of Science and Technology of Shandong Province through the project of independent innovation (No.2012CX80106)

The authors are with Sunrui Marine Environment Engineering Co., Ltd, Shandong, China (e-mail: ddx_tree@163.com, Yaop@sunrui.net, Liugz@sunrui.net, liuxl@sunrui.net, Dingh@sunrui.net). operations and hydrocyclone. In the process of disinfection, chemical inactivation such as oxidizing biocides and non-oxidizing biocides and physicochemical inactivation such as UV light, heat, cavitation and deoxygenation were used [6]-[9]. Among them electrolytic treatment technology has distinguished itself as the most promising one, due to its advantages of onsite generation of oxidants, good inactivation efficacy, low energy consumption and low foot print [10].

Chlorine $\left(\mathrm{Cl}_{2}\right)$ was generated by electrolyzing natural sea water. This chlorine gas rapidly dissolves into sea water to form free active chlorine (a mixture of hypochlorous acid $(\mathrm{HClO})$ and hypochlorite ion $\left(\mathrm{ClO}^{-}\right)$). Free active chlorine was found to react rapidly with glutathione, ascorbate, taurine, GSH and so on. Besides, free active chlorine was found cable of oxidising NADH and DNA. Protein, amino acid and DNA are highly abundant in marine organisms [11], [12]. Thus neutral electrolyzed water has a broad inactivation effect on marine organisms such as Escherichia coli, Enterococcus faecalis, Bacillus subtili sspore, Microcystisaeruginosa, Dunaliella salina and Artemia salina [13]-[15]. Besides HCLO and $\mathrm{CLO}^{-}$, electrolyzed water contain minor amount of hydroxyl radical, ozone, hydrogen peroxide and other $\mathrm{DBP}_{S}$ (disinfection byproducts) produced by the reaction of free chlorine with nitrogen compounds and organic compounds in sea water. All these chemical substance are called total residual oxidant.

The efficacy of electrolytic technology in the treatment of ballast water depends on the operating parameters of the electrolysis system, the initial concentration of total residual oxidant, and the kind of organisms. Among them, the concentration of total residual oxidant (TRO) was the most important. However, previous studies mainly concentrated on the operating parameters of electrolysis system and the inactivation efficacy of the electrolysis on different organisms. Only a few studies focused on the effect of sea water character on the efficacy of electrolytic method have been reported. The objective of this study is therefore to investigate the effects of temperature and organic carbon on the decay of total residual oxidant (TRO) in neutral electrolyzed water.

\section{MATERIALS AND METHODS}

\section{A. Preparation of Neutral Electrolyzed Water}

Neutral electrolyzed water (NEW) was prepared by electrolysing marine water. Electrolysis was performed under the galvanostatic conditions using an advanced electrochemical system (PARSTAT 2273, Priceton Applied Research, USA). A $5,500 \mathrm{~mL}$ single cell was used. A commercial DSA electrode (Supplied by Xian Taijin 
Industrial Electrochemical Technology Co., Ltd.) was used as anode. The anode was made of Ti and covered by Ru-Ir-Ta foil. The anode had a geometric area of $4 \mathrm{~cm}^{2}$. The cathode electrode was a Pt rod. The electric current was 0.8 A.

\section{B. The Effect of Temperature on TRO Decay}

Sea water filtered with $0.45 \mu_{\mathrm{m}}$ membrane was added to brown bottles. The cold traps (DC-1020, Changzhou Zhiborui equipment Co., LTD) were used to control the temperature of the water. The temperature was set at $10{ }^{\circ} \mathrm{C}, 15{ }^{\circ} \mathrm{C}$ and $25{ }^{\circ} \mathrm{C}$ respectively. Neutral electrolyzed water with high TRO concentration was produced using the method described in 2.1. After analysing the initial TRO concentration, appropriate amounts of electrolyzed water were added to brown bottles kept at $10{ }^{\circ} \mathrm{C}, 15^{\circ} \mathrm{C}$ and $25{ }^{\circ} \mathrm{C}$ respectively. The TRO concentration of water in brown bottle reached to 6.0 $7.0 \mathrm{mg} / \mathrm{L}$.

\section{The Effects of Organic Carbon on the Decay of TRO}

To determine the influence of organic carbon on TRO decay, appropriate amounts of glucose, sodium citrate, sucrose, chitosan and corn starch were added into 1,000 mL bottles to achieve levels of 5 and $10 \mathrm{mg} / \mathrm{L}$ respectively. The concentration of TRO in fresh prepared neutral electrolyzed water was analysed. Immediately after TRO analysis, neutral electrolyzed water was divided into $1,000 \mathrm{~mL}$ brown glass. Each 1,000 mL bottle was filled with $1000 \mathrm{~mL}$ neutral electrolyzed water. Samples were taken from $1,000 \mathrm{~mL}$ bottles at $2 \mathrm{~h}, 24 \mathrm{~h}, 96 \mathrm{~h}$ and $120 \mathrm{~h}$ respectively and analyzed for TRO concentration.

\section{Analytical Methods}

TRO was measured according to the standard method of $4500 \mathrm{Cl}-\mathrm{B}$ method I [16]. Put $50 \mathrm{~mL}$ sample in a flask, then place $5 \mathrm{ml}$ acetic acid in flask. Add about $1 \mathrm{~g}$ KI estimated on a spatula and mix with a stirring rod. Titrate away from direct sunlight. Add $0.025 \mathrm{~N} \mathrm{Na}_{2} \mathrm{~S}_{2} \mathrm{O}_{3}$, from a buret until the yellow color of the liberated iodine almost is discharged. Add $1 \mathrm{~mL}$ starch solution and titrate until blue color is discharged.

Total available residual chlorine calculated as:

$$
\text { mg } \mathrm{Cl} \text { as } \mathrm{Cl}_{2} / \mathrm{L}=(\mathrm{A} \pm \mathrm{B}) \times N \times 35450 / \mathrm{mL} \text { sample }
$$

where :

$$
\begin{aligned}
& A=\text { mL titration for sample } \\
& B=\text { mL titration for blank, and } \\
& N=\text { normality of } \mathrm{Na}_{2} \mathrm{~S}_{2} \mathrm{O}_{3}
\end{aligned}
$$

\section{RESULTS AND DISCUSSION}

\section{A. The Effect of Temperature on the Decay of TRO}

In order to study the effect of temperature on the decay of TRO, neutral electrolyzed water was kept at three temperature level $\left(10{ }^{\circ} \mathrm{C}, 15{ }^{\circ} \mathrm{C}\right.$ and $\left.25{ }^{\circ} \mathrm{C}\right)$. The concentrations of TRO in neutral electrolyzed water were analyzed during $120 \mathrm{~h}$ (Fig. 1) In the first $7 \mathrm{~h}$, all of TRO at different temperature decreased sharply and the decay rate were almost at the same rate. Then the TRO at $15^{\circ} \mathrm{C}$ decayed much faster than that at $10{ }^{\circ} \mathrm{C}$. After $72 \mathrm{~h}$, the difference of TRO decay rate between the samples at $10{ }^{\circ} \mathrm{C}$ and $15^{\circ} \mathrm{C}$ became less. After $7 \mathrm{~h}$, TRO at $25^{\circ} \mathrm{C}$ decayed significantly faster, compared with that at $10{ }^{\circ} \mathrm{C}$ and $15^{\circ} \mathrm{C}$. At $25{ }^{0} \mathrm{C}$, about $56 \%$ of TRO decreased in $120 \mathrm{~h}$ storage. The results of Fig. 1 indicated that high temperature may result in rapid decay of TRO. TRO was an important factor in ballast water treatment. The initial concentration and decay rate of TRO have a great effect on the efficiency of inactivation. When initial TRO concentration was decided in ballast water treatment, the temperature of ballast water should be given to enough attention.

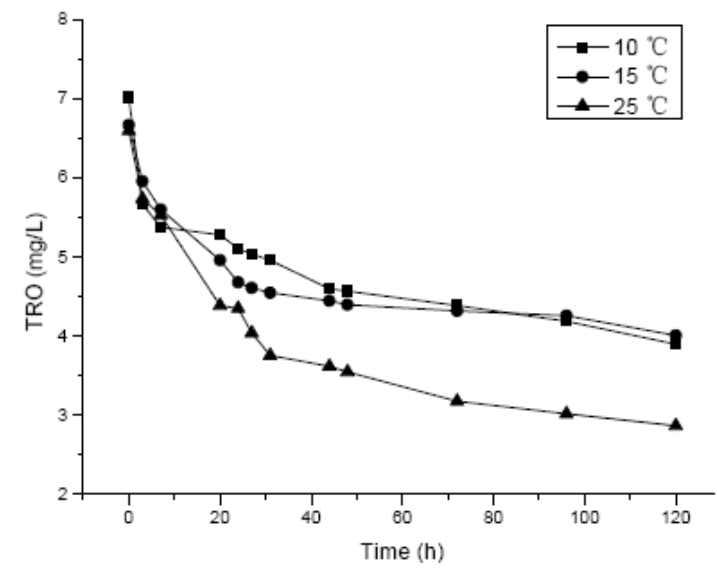

Fig. 1. The effect of temperature on the decay of TRO

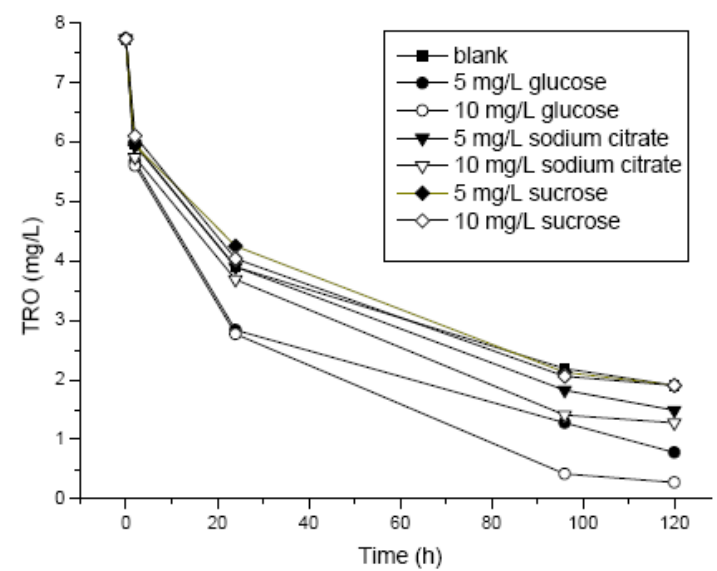

Fig. 2. The decay of TRO exposed to glucose, citrate and sucrose.

\section{B. The Effect of Dissolved Organic Carbon on TRO Decay}

To study the effect of dissolved organic carbon on TRO decay, neutral electrolyzed water was produced by electrolysing sea water. The initial TRO concentration was $7.73 \mathrm{mg} / \mathrm{L}$. After analysing TRO, the neutral electrolyzed water was divided into brown bottle which had been added glucose, citrate and sucrose respectively. The TRO concentrations in neutral electrolyzed sea water during $120 \mathrm{~h}$ were analyzed (Fig. 2.). During the first $24 \mathrm{~h}$, the TRO including blank sample decayed sharply. Among glucose, citrate and sucrose, the TRO in the sample with glucose decayed quickest and sucrose decayed slowest. The TRO with $5 \mathrm{mg} / \mathrm{L}$ organic carbon decayed more slowly than the level of $10 \mathrm{mg} / \mathrm{L}$. Glucose has a carbonyl group, which means that glucose is a reducing sugar. The result of Fig. 2 indicated glucose could reduce TRO. Fig. 2 also showed that citrate had reducing power too. The carbon-carbon bond with hydroxyl in citrate may be broken by $\mathrm{HClO}$ and was oxidized to carbon dioxide. Among the three kind of dissolved organic carbon tested, glucose had no obvious effect on TRO decay. 


\section{The Effect of Particle Organic Carbon on TRO Decay}

To study the effect of particle organic carbon on TRO decay, appropriate amounts of chitosan and corn starch were added to neutral electrolyzed water. The initial TRO concentration was $7.80 \mathrm{mg} / \mathrm{L}$. The concentrations of TRO in neutral electrolyzed sea water during $120 \mathrm{~h}$ were analyzed (Fig. 3). The TRO with chitosan decayed quicker than the blank. The TRO with $10 \mathrm{mg} / \mathrm{L}$ chitosan decayed quicker than that one with $5 \mathrm{mg} / \mathrm{L}$. However corn starch had no effect on TRO decay in neutral electrolyzed water. Chitosan used in this study were prepared by alkaline $\mathrm{N}$-deacetylation of crab chitin. Chitosan at high level (5-10 mg/L) could promote TRO decay. However at low level this effect was not obvious (the data were not shown).

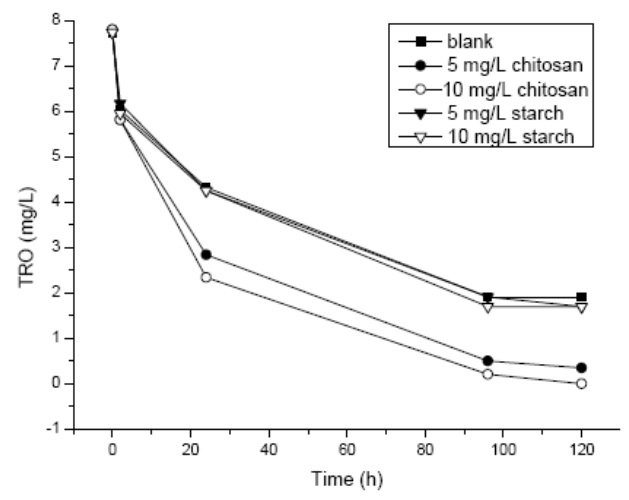

Fig. 3. The decay of TRO exposed to chitosan and corn starch.

The results of Fig. 2 and Fig. 3 indicated that the effect of organic carbon depended on the kinds and amount of organic carbon. Thus when electrolytic technology was used to treat ballast water, the composition of water should be analysed before deciding the initial TRO concentration. In addition, sucrose and chitosan had little effect on the concentration of TRO in neutral electrolyzed water. They were good choice for dissolved organic carbon and particle organic carbon to adjust inflow water in land based testing of ballast water manage system.

\section{CONCLUSIONS}

In this paper, the effect of environment parameters on the decay of TRO was investigated. The following conclusions can be drawn from the results obtained in this work:

- High temperature promoteed TRO decay. This effect was more obvious, when the temperature reached to $25{ }^{\circ} \mathrm{C}$.

- The effect of organic carbon was dependent on the kind and amount of organic carbon. Glucose, citrate, chitosan could promote TRO decay. With the level of these organic substances increasing, the TRO decayed more rapidly.

- In addition, sucrose and corn starch had no effect on TRO decay.

- Our results indicated that when electrolytic technology were used to treat ballast water, the temperature and composition of marine water should be tested before initial TRO concentration was decided.

\section{ACKNOWLEDGMENT}

This study was supported by Department of Science and
Technology of Shandong Province through the project of independent innovation (No.2012CX80106).

\section{REFERENCES}

[1] M. R. First, S. H. R. Wamsley, S. C. Riley, C. S. Moser, G. E. Smith, M. N. Tamburriand, and L. A. Drake, "Stratification of living organisms in ballast tanks: How do organism concentrations vary as ballast water is discharged?" Environmental Science and Technology, vol. 47, pp. 4442-4448, 2013.

[2] K. J. Carney, J. E. Delany, S. Sawant, and E. Mesbahi, "The effects of prolonged darkness on temperate and tropical marine phytoplankton and their implications for ballast water risk management," Marine Pollution Bulletin, vol. 62, pp. 1233-1244, 2011.

[3] J. S. B. Christopher and F. S. Miguel, "A review of the molecular evidence for ballast water introduction of the toxic dinoflagellates gymnodinium catenatum and the alexandrium tamarensis complex to Australasia," Harmful Algae, vol. 4, pp. 465-485, 2007.

[4] L. A. Drake, M. N. Tamburri, M. R. First, G. J. Smith, and T. H Johengen, "How many organisms are in ballast water discharge? A frame work for validating and selecting compliance monitoring tools," Marine Pollution Bulletin, vol. 1-2, pp. 122-128, 2014.

[5] G. Z. Liu, J. M. Wang, J. Q. Zhang, and C. N. Cao, "Effect of electrolytic treatment of ballast water on the corrosion behaviour of 316L stainless steel," Acta Metallurgica Sinica, vol. 12, pp. 1600-1604, 2011.

[6] K. G. N. Nanayakkara, Y. M. Zheng, A. K. M. K. Alam, S. W. Zou, and J. P. Chen, "Electrochemical disinfection for ballast water management: Technology development and risk assessment," Marine Pollution Bulletin, vol. 36, pp. 119-123, 2011.

[7] W. A. Prütz, "Hypochlorous acid interactions with thiols, nucleotides, DNA, and other biological substrates," Archives of Biochemistry and Biophysics, vol. 332, pp. 110-120, 1996.

[8] Y. Jung, Y. Yoon, E. Hong, M. Kwon, and J. W. Kang, "Inactivation characteristics of ozone and electrolysis process for ballast water treatment using B. subtilis spores as a probe, "Marine Pollution Bulletin, vol. 1, pp. 71-79, 2013.

[9] L. K. Folkes, L. P. Candeias, and P. Wardman, "Kinetics and mechanisms of hypochlorous acid reactions," Archives of Biochemistry and Biophysics, vol. 323, pp. 120-126, 1995.

[10] K. G. N. Nanayakkara, Y. M. Zheng, A. K. M. K. Alam, S. W. Zou, and J. P. Chen, "Electrochemical disinfection for ballast water management: Technology development and risk assessment," Marine Pollution Bulletin, vol. 63, pp. 119-123, 2011.

[11] W. A. Prütz, "Hypochlorous acid interactions with thiols, nucleotides, DNA, and other biological substrates," Archives of Biochemistry and Biophysics, vol. 332, pp. 110-120, 1996.

[12] D. I. Pattison, C. L. Hawkins, and M. J. Davies, "Hypochlorousacid mediated protein oxidation: How important are chloramine transfer reactions and protein tertiary structure," Biochemistry, vol. 46, pp. 9853-9864, 2007.

[13] D. Wu, H. You, J. Du, C. Chen, and D. Jin, "Effects of UV/Ag-TiO2/O3 advanced oxidation on unicellular green alga Dunaliella salina: Implications for removal of invasive species from ballast water," Journal of Environmental Sciences, vol. 23, pp. 513-519, 2011.

[14] W. Liang, J. Qu, L. Chen, H. Liu, and P. Lei, "Inactivation of Microcystis aeruginosa by continuous electrochemical cycling process in tube using $\mathrm{Ti} / \mathrm{RuO}_{2}$ electrodes," Environmental Science and Technology, vol. 39, pp. 4633-4639, 2005.

[15] E. Solaki, P. Pitta, and E. Diamadopoulos, "Electrochemical disinfection of simulated ballast water using Artemia salina as indicator," Chemical Engineering Journal, vol. 156, pp. 305-312, 2010.

[16] A. D. Eaton, L. S. Clesceri, E. W. Rice, and A. E. Greenberg, Standard Methods for the Examination of Water and Waste Water, 21st ed., AWWA/APHA/WEF, 2005.

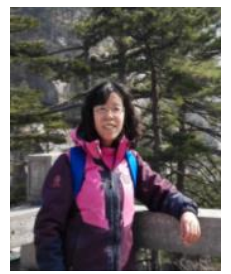

Dongxia Duan was born in 1976. She graduated in microbiology from Northwest University in 2002. She completed her Ph.D. degree in marine biology from Ocean University of China in 2010.

She is currently working as a senior engineering at the Department of Research and Development of Sunrui Marine Environmental Engineering Co., Ltd., Shandong Province China. Her research interests include water treatment, biofouling and micro influenced corrosion. 


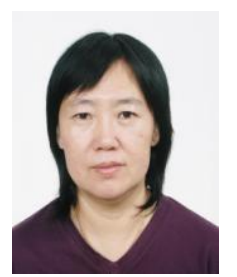

Ping Yao was born in 1965. She graduated from Tianjin University with a bachelor's degree in electrochemistry in 1987 and earned a master's degree from the Oklahoma Central University, in USA in 2003.

She is working at Sunrui Marine Environment Engineering Co., Ltd. as an senior engineer. Her interests are cathodic protection and ballast water management. Her research achievements have made application successfully in marine engineering.

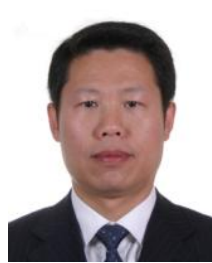

Guangzhou Liu was born in 1969. He acquired his bachelor degree and master degree in electrochemical from Haerbing Institute of Technology. He completed his $\mathrm{Ph} . \mathrm{D}$. degree in physical chemistry from Zhejiang University in 2011.

$\mathrm{He}$ is currently working as a researcher at Sunrui Marine environmental Engineering Co., Ltd. He works in the field of water treatment and corrosion control. His work has been published in international journals.

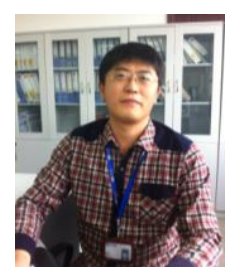

Xuelei Liu was born in 1982. He graduated in testing technology and instrument from Haerbing Institute of Technology.

$\mathrm{He}$ works as an engineering at Sunrui Marine Environmental Engineering Co., Ltd., Shandong Province China. He is working in the field of ballast water.

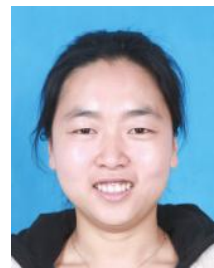

Hui Ding was born in 1980. She graduated in bioengineering from Dalian Polytechnic University in 2003. She got her master degree in applied chemistry from University of Science and Technology Liaoning in 2008.

She is currently working for Sunrui Marine Environmental Engineering Co., Ltd. She is working in the field of water treatment and biofouling control. 